\title{
Short-Time Dynamics of pH-Dependent Conformation and Substrate Binding in the Active Site of Beta-Glucosidases: A Computational Study
}

David F. Flannelly, ${ }^{1}$ Thalia G. Aoki, ${ }^{2}$ and Ludmilla Aristilde ${ }^{1,2, *}$

${ }^{1}$ The Institute for Comparative and Environmental Toxicology and ${ }^{2}$ Department of Biological and

Environmental Engineering, College of Agricultural and Life Sciences, Cornell University, Ithaca, NY 14853, USA

\section{Corresponding Author:}

L.A.: Department of Biological and Enviornmental Engineering, Cornell University, 214 Riley-Robb Hall, Ithaca, NY 14853 USA. Phone: (607) 255-6845. Fax: (607) 607.255.4449. E-mail: ludmilla@ cornell.edu 


\section{ABSTRACT}

The complete degradation of cellulose to glucose is essential to carbon turnover in terrestrial ecosystems and to engineered biofuel production. A rate-limiting step in this pathway is catalyzed by beta-glucosidase (BGs) enzymes, which convert cellulobiose into two glucose molecules. The activity of these enzymes has been shown to vary with solution $\mathrm{pH}$ but the influence of $\mathrm{pH}$ of the enzyme conformation required for catalytic action on the substrate is not well understood. We applied molecular dynamics simulations to explore conformational and substrate binding dynamics in two well-characterized BGs of bacterial (Clostridium cellulovarans) and fungal (Trichoderma reesi) origins as a function of $\mathrm{pH}$. The enzymes were simulated in an explicit solvated environment, with $\mathrm{NaCl}$ as electrolytes, at their prominent ionization states obtained at $\mathrm{pH} 5,6,7$, and 7.5. Our findings indicated that $\mathrm{pH}$-dependent changes in the ionization states of non-catalytic residues localized outside of the immediate active site led to $\mathrm{pH}$-dependent disruption of favorable H-bonding interactions with catalytic residues required to initiate catalysis on the substrate. We also identified specific non-catalytic residues that are involved in stabilizing the substrate at the optimal $\mathrm{pH}$ for enzyme activity. The simulations further revealed the dynamics of water-bridging interactions both outside and inside the substrate binding cleft during structural changes in the enzyme-substrate complex. These findings provide new insights into the $\mathrm{pH}$-dependent substrate binding specificity in BGs.

\section{Keywords:}

Cellulose degradation

Enzyme catalysis

$\mathrm{pH}$ effect

\section{Molecular modeling}

\section{Introduction}

Beta-glucosidases (BGs) catalyze the cleavage of the 1-4 beta-linkage of cellulobiose (or cellobiose), a glucose dimer, to produce two glucose molecules. ${ }^{1}$ This cleavage is a rate limiting step in the complete degradation of cellulose to glucose. ${ }^{1,2}$ A comprehensive understanding of the functional dynamics of BGs under different aqueous conditions is needed to predict the contributions of these enzymes to terrestrial carbon fluxes ${ }^{3-}$ 5 and in engineered biofuel production from lignocellulosic wastes. ${ }^{1,6-8}$ Both in natural environments and in engineered bioreactors, BGs are exposed to various aqueous $\mathrm{pH}$ values, ranging from acidic to alkaline conditions. ${ }^{9-12}$ Because enzymes are comprised of ionizable amino acid residues, $\mathrm{pH}$ impacts their conformation, structural stability, and catalytic activity. ${ }^{13}$

A large diversity of $\mathrm{pH}$-activity profiles exists for BGs of different origins, and even within the same species. ${ }^{14}$ For instance, maximum enzymatic activities of BGs from the anaerobic bacterium Clostridium cellulovorans $^{2}$, the fungi Asperigillus aculeaus ${ }^{15}$ and Trichoderma reesi ${ }^{2}$, and the insect Chilo suprressalis ${ }^{16}$ occur, respectively, at $\mathrm{pH}$ values of $6,3,6$, and 9. A mechanistic basis for the relationship between enzyme 
structure and $\mathrm{pH}$-induced effects on BG activity is lacking. In the present study, we seek to explore this relationship in two enzymes belonging to the family 1 of $\mathrm{BGs}^{2}$, one from the bacterium $C$. cellulovorans and one from the fungus $T$. reesi, which have well defined crystal structures. Both of these enzymes have been shown experimentally to exhibit optimal catalytic activity at $\mathrm{pH}$, with decreased activity at higher and lower $\mathrm{pH}$ values. $^{2}$ The catalytic action on the substrate in family 1 BGs has been well characterized but the structural dynamics underlying the $\mathrm{pH}$-dependent substrate specificity have not been fully examined.

Catalysis in family $1 \mathrm{BGs}$ is mediated by two Glu residues: an acidic/basic Glu residue and a nucleophilic Glu residue (Scheme 1). Protonation of the linking C1-C1' O atom (O1) of the substrate by the acidic/basic Glu residue $\left(\right.$ Glu166 $6_{\text {bacterial }} /$ Glu165 fungal $)$ sets the stage for a nucleophilic attack by the other catalytic Glu residue (Glu352 $2_{\text {bacterial } / G l u 367_{\text {fungal }} \text { ) on the } \mathrm{C} 1 \text { of the substrate }}{ }^{2,17,18}$ (Scheme 1; Fig. 1). A transition state facilitates the splitting of the C1-C1' link while retaining a covalent bond with the nucleophilic Glu ${ }^{17}$ (Scheme 1). The reaction is completed by the release of the cleaved part of the substrate following the de-glycosylation step (Scheme 1). The initiation of the catalytic action is mediated by a H-bonding interaction between the substrate $\mathrm{O} 1$ and the acidic/basic Glu. ${ }^{2,18}$ Thus, the disruption of this H-bonding interaction would impede forward catalytic steps. The effect of $\mathrm{pH}$ on this key interaction has not been determined.

The nucleophilic Glu residue plays an integral role in stabilizing the intermediate state in the hydrolysis reaction ${ }^{17}$ but its role in substrate binding is unresolved. In structures of BGs co-crystallized with substrates in the active site, ${ }^{19,20}$ the nucleophilic Glu has adopted an orientation that can facilitate the formation of a H-bond with the $\mathrm{H}$ atom connected to the $\mathrm{O} 2$ (i.e. $\mathrm{H}_{\mathrm{O} 2}$ ) of the substrate. This $\mathrm{H}$-bond could thus aid in orienting the substrate towards a favorable interaction with the catalytic acidic/basic Glu. However, due to the geometry of the nucleophilic Glu $\cdots \mathrm{H}_{\mathrm{O} 2} \mathrm{H}$-bond, this bond would have to be broken prior to the nucleophilic attack by the Glu on the $\mathrm{C} 1$ of the substrate in the second catalytic step (Scheme 1). ${ }^{21}$ Therefore, a strong interaction between the nucleophilic Glu and $\mathrm{H}_{\mathrm{O} 2}$ could impede catalysis. The occurrence of this interaction during pH-dependent structural changes in the enzyme remains to be elucidated.

In addition to the catalytic Glu residues, the substrate binding cleft has several non-catalytic amino acid residues, which are highly conserved in family 1 BGs (Fig. 1): an Asn (Asn165 $5_{\text {bacterial }} /$ Asn $164_{\text {fungal }}$ ) residue that immediately precedes the acidic/basic catalytic glutamate residue, a Gln residue $\left(\mathrm{G} \ln 20_{\text {bacterial }} / \mathrm{Gln} 16_{\text {fungal }}\right)$ and a Glu residue $\left(\right.$ Glu $\left.406_{\text {bacterial }} / \mathrm{Glu} 424_{\text {fungal }}\right)$ which form two H-bonds with the substrate, a Tyr residue (Tyr296 bacterial $/$ Tyr298 $_{\text {fungal }}$ ) which participates in the removal of the bound intermediate, a His residue (His $121_{\text {bacterial }} /$ His $119_{\text {fungal }}$ ) which mediates the initial binding of the substrate, and a Trp residue $\left(\operatorname{Trp} 407_{\text {bacterial }}\right.$ /Trp425 fungal) (Fig. 1). ${ }^{18}$ These non-catalytic residues have been evaluated for their individual energetic contributions to the catalytic hydrolysis. ${ }^{18}$ However, similar to the catalytic Glu residues, the involvement of the conserved non-catalytic residues in the substrate binding under unfavorable $\mathrm{pH}$ conditions has not yet been investigated.

It is widely accepted ${ }^{18,20,22-24}$ that water plays an essential role in the BG hydrolysis pathway by stabilizing the active site-bound substrate and intermediate as well as participating in interactions that mediate the release 
of the final product. It is challenging to capture directly the dynamics of water molecules in enzyme-substrate interactions via experimental means. Consequently, the role of water in the stabilization of the substrate ${ }^{20}$ and the intermediate ${ }^{18}$ has been inferred from the positioning of $\mathrm{O}$ atoms in X-ray crystal structures. For instance, the geometry of a BG co-crystallized with a glucose polymer suggested that amino acid residues outside of the immediate active site can interact with the substrate through water bridges. ${ }^{20}$ A quantum mechanical (QM) analysis has demonstrated that water molecules are especially important in the thermodynamically-favorable binding of the intermediate during BG hydrolysis. ${ }^{18}$ Studies on the dynamic role of water interactions in mediating $\mathrm{pH}$-dependent substrate binding are lacking.

We hypothesize that $\mathrm{pH}$-dependent substrate specificity in BGs may result from three main phenomena: (1) changes in ionization states in amino acid residues in the substrate binding pocket alter substrate-binding interactions, (2) $\mathrm{pH}$-induced changes in the ionization states of non-active site residues lead to conformational changes in the active site, and/or (3) changes in enzyme conformation disrupt stabilization by water interactions.

Previous mutagenesis studies have shown that non-catalytic residues of BGs and of other similar classes of enzymes can impact enzyme activity and substrate specificity. ${ }^{25-27}$ In support of the second hypothesis presented above, a study on the effects of site-directed mutagenesis on the $\mathrm{pH}$-activity profile of a cellulase from T. reesi ${ }^{27}$ reported that mutations in certain amino acid residues on the surface of the enzyme can result in up to 0.6 unit decrease or up to a 1.4 unit increase in the optimal $\mathrm{pH}$ for enzyme activity. The mechanisms responsible for these $\mathrm{pH}$ shifts for optimal activity were not resolved. In another study on an exocellulase from T. reesi, ${ }^{28}$ mutations of carboxyl-carboxyl pairs into amide-carboxyl pairs led to increased activity of the enzyme at higher $\mathrm{pH}^{28}$ In this study ${ }^{28}$, it was proposed that the deprotonated carboxyl-carboxyl pairs, which would repulse each other, reduced the stability of the enzyme and impede activity at high $\mathrm{pH}$; thus, substituting an amide group for one of the interacting carboxyls would reduce the repulsion, increase stability, and augment activity. The implication of this change in stability on the $\mathrm{pH}$-dependent catalytic binding dynamics was not evaluated.

In silico methods, via both QM and molecular dynamics (MD) simulations, have been applied to analyze reaction mechanisms and reaction pathways in enzyme catalysis. ${ }^{29-31}$ Previous QM molecular modeling of every step along the BG catalytic pathway identified specific amino acids that stabilize the substrate binding at various points during the enzymatic action. ${ }^{18,24}$ The influence of $\mathrm{pH}$ on the catalytic substrate binding in the BG active site, however, has not yet been studied. Performing MD simulations circumvents the limitation of QM studies to capture the conformational dynamics of enzyme structures as a function of changes in $\mathrm{pH} .{ }^{32-36}$ For instance, a MD study ${ }^{35}$ of a proteinase in response to different ionization states of non-catalytic residues in the active site reported $\mathrm{pH}$-dependent binding site perturbations that may be responsible for the experimentally-obtained $\mathrm{pH}$ activity profile. ${ }^{35}$ With respect to $\mathrm{BGs}$, one MD study investigated the binding dynamics of several known inhibitors whereby the inhibitors assumed different protonation states. ${ }^{37}$ To the best of our knowledge, the structural dynamics underlying the $\mathrm{pH}$-dependent $\mathrm{BG}$ catalytic action on the substrate have not been characterized. 
Building on these previous experimental and modeling studies, the present study adopts an in silico approach to explore the structural factors responsible for the $\mathrm{pH}$-dependent substrate binding dynamics in the two aforementioned family $1 \mathrm{BGs}$ from $C$. cellulovorans and from $T$. reesi. We aim (1) to identify the active site and non-active site amino acid residues responsible for changes in the enzyme's ionization states as a function of $\mathrm{pH},(2)$ to determine the consequence of these changes on the favorable substrate binding required for catalysis, and (3) to explore the participation of solvated waters in mediating substrate binding. To meet these objectives, we applied a modeling methodology, which combined molecular docking, energy minimization (EM), and MD algorithms, to conduct molecular simulations of the two enzymes in an explicit solvated

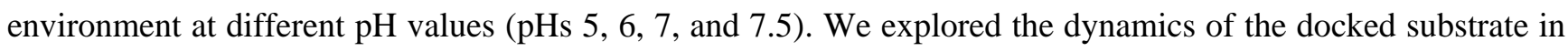
the active site and monitored intermolecular interactions with catalytic residues as well as non-catalytic residues. ${ }^{18}$ In addition, the explicit solvation approach allowed us to monitor the dynamic role of water molecules both in solvating the substrate and in bridging interactions between the substrate and the enzyme. Our MD-equilibrated structures thus provide mechanistic insights into towards elucidating the link between experimentally-determined $\mathrm{pH}$-dependent activity and $\mathrm{pH}$-induced structural changes in BGs.

\section{Computational Methods}

\subsection{Modeling Platform}

Molecular simulations were performed using the forcefield CHARMm (Chemistry at HARvard Molecular Mechanics $),{ }^{38}$ as interfaced through Accelrys's Discovery Studio software package. ${ }^{39}$ This forcefield was previously validated ${ }^{38,40}$ to simulate structures of peptides and proteins.

\subsection{Validation Simulations of a termite BG}

As a pre-requisite to performing the simulations of the bacterial (C. cellulovorans; PDB ID 3AHX ${ }^{2}$ ) and fungal (T. reesi; PDB ID 3AHY ${ }^{2}$ ) BGs, we developed a methodology for docking and simulating the substrate in the active site (Fig. 2). Because no structural data are available for the aforementioned BGs with a substrate in the active site, we validated our methodology using the structure of another family $1 \mathrm{BG}$ of termite origin (Neotermes koshunsis; PDB ID 3VIL ${ }^{19}$ ), which was crystallized with a substrate surrogate (salicin) in its active site.

For the modeling validation, the ionization states of the residues of the termite enzyme were simulated at the same aqueous conditions ( $\mathrm{pH} 7.25,0.15 \mathrm{M} \mathrm{NaCl})^{19}$ used for the protein's crystallization by using an algorithm ${ }^{41}$ as implemented in Discovery Studio. ${ }^{41}$ This algorithm assesses the local environment of each amino acid residue with respect to other residues in the protein structure and the degree of exposure of the amino acid residue to the solvent in order to compute the prominent ionization states of each amino acid residue. Before the substrate docking, the residue Glu402 termite $^{19}$ was manually deprotonated to reflect the known catalytic ionization state of the nucleophilic base. ${ }^{17}$ The substrate (salicin) was docked into the active site of the enzyme using the CHARMm docking software CDOCKER. ${ }^{42}$ The interaction sphere (radius of $7 \AA$ ) was defined to include the 
residues, which were shown to interact with the substrate in the crystal structure. ${ }^{19}$ The additional docking parameters were the following: pose cluster radius $=0.1$, random conformations $=10$, dynamic steps $=1,000$, and simulated annealing heating to $700 \mathrm{~K}$ and then cooling to $300 \mathrm{~K}$ over 2,000 steps. The lowest-energy configurations were compared to the atomic coordinates of the original X-ray structure ${ }^{19}$ whereby successful dockings were evaluated by the conventional standard of Root Means Square Deviation (RMSD) of less than 2.0 $\AA^{43,44}$ The docked substrate had an RMSD of 0.382 , which met the criteria for a successful docking (Supplementary Table S1).

To achieve the background ionic solution $(0.15 \mathrm{M})$ in the solvated 3VIL protein with the docked substrate, the solvation algorithm in Discovery Studio implemented the $\mathrm{Na}$ and $\mathrm{Cl}$ ions were implemented to both balance charges on the enzyme and randomly in the solvated simulation box. The solvated system was subjected to two EM cycles (1,000 maximum steps each), heated simulation (300K for $4 \mathrm{ps}$ at $1 \mathrm{fs}$ time step), a MD equilibration run (for $10 \mathrm{ps}$ at $2 \mathrm{fs}$ time step) before the final MD run (1 ns at $2 \mathrm{fs}$ time step), from which data were retrieved. The modeling parameters used in the Discovery Studio were the following: NPT (constant pressure and temperature) ensemble with a Nose-Hoover thermostat to set the temperature and a Langevin piston for the pressure simulation; cutoff for nonbonded interactions was $14 \AA$; bonds involving hydrogen atoms were fixed; the TIP3P water model was used with the CHARMm forcefield

Six H-bonding interactions between the substrate and the enzyme, which were deduced from the crystal structure of the active site $^{2}$, were monitored throughout the simulations. The MD-predicted values for these $\mathrm{H}$ bond distances were within one standard deviation of the experimental values ${ }^{19}$ (Supplementary Table S1), thus demonstrating the ability of our modeling methodology to replicate appropriate configurations of the enzyme to facilitate favorable active site-substrate interactions in an aqueous condition very similar to our systems of interest.

\subsection{Molecular Simulations of the Bacterial and Fungal BGs}

Following the successful development and validation of our methodology, we employed a similar workflow to simulate the conformational and substrate binding dynamics of the bacterial and fungal BGs enzymes at the optimal $\mathrm{pH}$ for catalytic activity of these enzymes, $\mathrm{pH} \mathrm{6}$, as well as at $\mathrm{pH} \mathrm{5,} \mathrm{7,} \mathrm{and} 7.5$ (Fig. 2). After the enzymes were retrieved from the PDB database, they were prepared at each $\mathrm{pH}$ according to the aforementioned algorithm. ${ }^{41}$ Once the most prominent protonation states of the amino acid residues were determined at each $\mathrm{pH}$, they were not allowed to fluctuate over the course of the simulations while taking into account changes in intrinsic $\mathrm{pK}_{\mathrm{a}}$ values as a function of conformational dynamics as a function of simulation times. We acknowledge that this approach does not account for the simultaneous ensemble of (less prominent) protonation states that can exist in equilibrium at a given $\mathrm{pH}^{32,33,36,45-47}$. The focus of our study was to simulate the enzyme at its most probable ionization state under each $\mathrm{pH}$ condition.

In order to model the known starting catalytic ionization states, ${ }^{2}$ the nucleophilic Glu residue important for catalysis (Glu352 bacterial $_{\text {Glu367 fungal }}$ ) was deprotonated and the acidic/basic Glu residue 


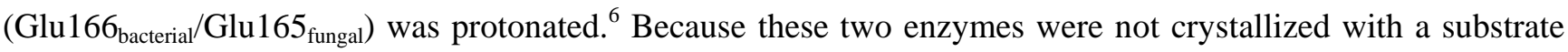
bound to the active site, it was necessary to obtain first the conformation required to accommodate the substrate. We achieved this conformation by overlaying the active site residues of each enzyme (3AHX and 3AHY) onto the termite (3VIL) active site, which was crystallized around a substrate analog (salicin). This superimposition was executed by creating tethered atom pairings between the atoms in the termite BG enzyme and those in each of the BG enzyme being studied. Specifically, $\alpha$ carbons of the 12 active site amino residues as well as the carboxylate moiety of the nucleophilic Glu were paired. Subsequently, the atom pairings were subjected to a geometry optimization step by minimizing the sum of the squared distances between all of the pairs. The initial orientation of the substrate (salicin) was oriented in both the bacterial and fungal active sites was informed by the binding orientation obtained with the crystal structures of the termite $\mathrm{BG}^{19}$ - our simulations were performed with salicin, a commonly-used substrate analog of the natural substrate cellobiose, because experimental studies of the relationship between $\mathrm{pH}$ and enzymatic activity for both enzymes were conducted with salicin. ${ }^{2}$ All systems were then solvated in a $0.1 \mathrm{M} \mathrm{NaCl}$ solution with explicit water molecules in a periodic environment. These solvated systems were subjected subsequently to a series of EM and MD series, as previously described, consisting of two minimization steps, a heating step, a preliminary MD equilibration step, followed by a $2 \mathrm{~ns}$ MD production step used for analysis.

We acknowledge that longer simulations are customary in molecular dynamics studies. We have also conducted longer MD simulations (up to $200 \mathrm{~ns}$ ) for the systems. However, throughout the course of $200 \mathrm{~ns}$ in several of the systems, we found that the substrate migrated outside of the substrate binding cleft, interacted with residues on the external periphery of the active site, and became increasingly solvated by water molecules (Supplementary Fig. S1 and Fig. S2). We attributed this phenomenon to the destabilization of unfavorable substrate binding interactions with the active site residues when the simulations are too long. Therefore, extended MD simulation time was not an appropriate approach here to examine the substrate binding structures across both favorable and unfavorable $\mathrm{pH}$ conditions wherein the enzyme conformations are not always optimal for substrate binding. In fact, it is this $\mathrm{pH}$-dependent unfavorable substrate binding that we are investigating in this study. The analysis of the migration of the substrate away from the active site was beyond the scope of the present study but will be investigated in the future. The shorter simulation period chosen for analysis allowed us to probe specifically $\mathrm{pH}$-dependent substrate binding with both catalytic and non-catalytic residues in the active site substrate remained in the active site for all the investigated $\mathrm{pH}$ conditions.

\subsection{Analysis}

The configurations used for analysis were retrieved from the MD production step. Mapping of the hydrophobic and hydrophilic regions on the enzyme was carried out using the last MD-optimized configuration. Hydrophobic surface mappings were generated using Discovery Studio algorithms that calculate the hydrophobic sections of the enzyme based on the chemical properties of each residue, as well as the chemical properties of the neighboring atoms. We monitored the dynamics of H-bonding interactions between the 
substrate and water molecules using Discovery Studio's experimentally-validated ${ }^{48,49}$ algorithm for non-bonding interactions to capture any potential H-bonding by setting a maximum $\mathrm{H}$-acceptor distance of $3.1 \AA$ and a range of donor-H-acceptor angles between several angles (all between 90-180 degrees). A more selective criteria (distance $<2.8 \AA$ and angles between 120-180 degrees) were applied to substrate-active site interactions to screen for stronger interactions. For statistical analysis, the 2000 ps (or 2ns) simulation was divided into 200 ps segments in order to obtain the mean and standard deviation of the presence of an interaction throughout the simulation. Statistical significance was determined using an unpaired two-tailed t-test comparison. Cooccurrence correlations between multiple interactions were analyzed using a Pearson's test, followed by a screening for significance using a $\mathrm{p}$-value $(\mathrm{p}<0.05)$ adjusted for multiple hypotheses and for a correlation strength of an $\mathrm{R}$ greater than or equal to 0.15 . Finally, we performed a RMSD analysis to explore the $\mathrm{pH}-$ dependent structural dynamics at the level of amino acid residues in the enzyme. The amino acid residues of interest were those that underwent a change in ionization states and those involved in catalytic, non-catalytic, and water-bridging interactions. For each residue of interest, we monitored the RMSD in distance from residue's starting position for each frame in the final MD run. A Pearson's correlation test of the RMSD fluctuations determined whether the residues were moving away from their original position at statistically-significant similar or distinct times. After the threshold for significance was adjusted to account for the number of correlation pairs tested, all non-significant correlations values were removed.

\section{Results}

\section{1. pH-Dependent Changes in Ionization States}

When obtaining the starting structure for each system as a function of $\mathrm{pH}$, we observed that several amino acid residues in both enzymes underwent changes in their prominent ionization states when the enzymes were subjected to increasing $\mathrm{pH}$ conditions (Table 1). In the bacterial enzyme, four amino acids (one Asp and three Glu) became negatively charged and one His went from being positively-charged to being neutral from $\mathrm{pH} 5$ to $\mathrm{pH}$ 6, one Glu residue became negatively charged and two His residues became neutral from $\mathrm{pH} 6$ to $\mathrm{pH} 7$, and one Glu became negatively charged and one His became neutral charge from pH 7 to pH 7.5 (Table 1). In the fungal enzyme, seven amino acids (four Asp and three Glu) became negatively charged from $\mathrm{pH} 5$ to $\mathrm{pH}$ 6, one Asp became negatively charged and one His became neutral from $\mathrm{pH} 6$ to $\mathrm{pH} 7$, and three His residues went from being positively charged to neutral from $\mathrm{pH} 7$ to $\mathrm{pH} 7.5$ (Table1). Therefore, the bacterial enzyme gained five negative charges from $\mathrm{pH} 5$ to $\mathrm{pH} 6$ and two additional ones from $\mathrm{pH} 6$ to $\mathrm{pH} 7.5$; the fungal enzyme gained 7 negative charges from $\mathrm{pH} 5$ to $\mathrm{pH} 7$ and five additional ones from $\mathrm{pH} 6$ to $\mathrm{pH} 7.5$ (Table 1).

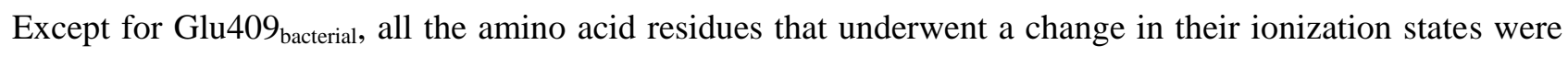
located outside of the substrate-binding cleft, as illustrated in Fig. 3A and Fig. 3B. It is important to note, as stated in the introduction, that $\mathrm{pH} 6$ is the optimal $\mathrm{pH}$ for enzyme activity for the two enzymes, with decreased activity recorded at $\mathrm{pH}$ values lower and higher than $\mathrm{pH} 6 .^{2}$ Surface mappings of the hydrophobic and hydrophilic regions of each enzyme illustrated the consequence of the $\mathrm{pH}$-dependent changes in the ionization 
states on the conformation of the substrate-binding cleft (Fig. 3 and supplementary Fig. S3). Noticeably, the overall hydrophilic nature of the substrate-binding cleft persisted under all four $\mathrm{pH}$ conditions, which is consistent with the lack of major changes in the ionization states of active site residues at the different $\mathrm{pH}$ conditions. However, this did not preclude structural changes in the substrate-binding pocket, as shown in Fig. 3. These conformational changes around the active site may induce disruption of favorable substrate binding dynamics required for catalysis in the BG enzymes. We explored these changes in binding dynamics in the following sections.

\section{2. pH-Induced Changes in Substrate Interactions with Catalytic and Non-Catalytic Residues}

As discussed in the Introduction, the hydrolytic catalysis is initiated by the Glu166 bacterial $\cdots \mathrm{O} 1 /$ Glu $165_{\text {fungal }} \cdots \mathrm{O} 1$ interaction. ${ }^{2,18}$ The simulations with the bacterial enzyme revealed that the catalytic Glu166 $6_{\text {bacterial }} \cdots \mathrm{O} 1$ interaction was the most abundant at $\mathrm{pHs} 6,7$, and 7.5 but occurred significantly less at $\mathrm{pH} 5$ than at $\mathrm{pH} 6$ (Fig. 4). We also observed that the occurrence frequency of the $\mathrm{H}_{\mathrm{O} 2} \cdots \mathrm{Glu}_{166}$ bacterial interaction followed a similar pattern as the catalytic interaction Glu166 bacterial $\cdots \mathrm{O} 1$, peaking around $\mathrm{pH} 6$ and then decreasing at higher and lower $\mathrm{pH}$ values (Fig. 4) - this trend is analogous to the experimental $\mathrm{pH}$-activity profile. $^{2}$

The MD results with the catalytic Glu165 fungal $\cdots \mathrm{O} 1$ interaction in the fungal enzyme was the highest at the $\mathrm{pH}$ values of 6 and 7; and, the abundance of the interaction at the enzyme's optimal $\mathrm{pH}$ of 6 was statistically higher than at $\mathrm{pH} 5$ or $\mathrm{pH} 7.5$ (Fig. 5). The $\mathrm{H}_{\mathrm{O} 2} \cdots$ Glu165 fungal interaction occurred at a higher abundance at the catalytically-optimal $\mathrm{pH}$ of 6 than at the other $\mathrm{pH}$ values. This interaction correlated strongly with the occurrence of the catalytic Glu165 fungal $\cdots \mathrm{O} 1$ interaction (Fig. 5). These findings with both enzymes indicate that the catalytic H-bond between the carboxylic acid moiety of Glu166 bacterial $/ \mathrm{Glu} 165_{\text {fungal }}$ and the substrate $\mathrm{O} 1$ atom was stabilized by a H-bond between the carbonyl group of the Glu residue and the $\mathrm{OH}$ group adjacent to $\mathrm{O} 1$ of the substrate (Fig. 4 and Fig. 5). Moreover, the MD results predicted substrate binding dynamics in the fungal enzyme that mirrored more the experimental $\mathrm{pH}$ activity profile than the corresponding dynamics with the bacterial enzyme. $^{2}$

For a more comprehensive exploration of the dynamic interactions that are pre-requisite to favorable binding of the substrate, we also monitored $\mathrm{pH}$-dependent changes in the interactions of the substrate with other residues in the substrate-binding cleft. First, we investigated the interactions with the nucleophilic Glu (Glu352 bacterial $_{\text {Glu367 }}$ fungal $)$, whose interactions during substrate binding are not well understood. In the MD simulations of the bacterial $\mathrm{BG}$, the abundance of the nucleophilic Glu interaction, $\mathrm{H}_{\mathrm{O} 2} \cdots \mathrm{Glu} 352_{\text {bacterial }}$, exhibited the same trend as the catalytic Glu $166_{\text {bacterial }} \cdots \mathrm{O} 1$ interaction: minimal abundance at $\mathrm{pH} 5$, highest abundance at $\mathrm{pH}$ 6, and statistically similar abundance for $\mathrm{pH} 7$ and pH 7.5 (Fig. 4). Furthermore, the Pearson's test for co-occurrence correlation revealed that the presence of the $\mathrm{H}_{\mathrm{O} 2} \cdots \mathrm{Glu} 352_{\text {bacteiral }}$ interaction (or the presence of a pair of interactions that include the $\mathrm{H}_{\mathrm{O} 2} \cdots \mathrm{Glu} 352_{\text {bacterial }}$ ) correlated with the occurrence of the catalytic Glu166 bacterial $\cdots \mathrm{O} 1$ interaction at $\mathrm{pH} 5,6$, and 7 (SI, Table S2). On the other hand, in the simulations of 
the fungal enzyme, there was no correlation between the $\mathrm{pH}$-dependent trend of the frequency abundances of the nucleophilic Glu interaction ( $\mathrm{H}_{\mathrm{O} 2} \cdots$ Glu367 fungal $)$ and the acidic/basic Glu interaction (Glu165 fungal $\left.\cdots \mathrm{O} 1\right)$ (Fig. 5). The decoupling of these two interactions was especially evident at $\mathrm{pH} 7$ and 7.5 where the $\mathrm{H}_{\mathrm{O} 2} \cdots \mathrm{Glu}_{367}$ fungal was highly abundant whereas there was little to no occurrence of the Glu165 fungal $\cdots \mathrm{O} 1$ interaction at these $\mathrm{pH}$ values. Correlation analysis confirmed this lack of significant co-occurrence of these interactions (Supplementary Table S2).

In addition to the two catalytic Glu residues, we examined the $\mathrm{pH}$-dependent dynamics of substrate interactions with non-catalytic active site residues (Fig. 4 and Fig. 5; supplementary Fig. S4 and S5). As listed in the Introduction, the relevant non-catalytic residues $\left(\mathrm{G} \ln 20_{\text {bacterial }} / \mathrm{G} \ln 16_{\text {fungal }}, \mathrm{Glu} 406_{\text {bacterial }} / \mathrm{Glu} 424_{\text {fungal }}\right.$, Tyr296 bacterial $/$ Tyr298 fungal, His121 $1_{\text {bacterial }} /$ His $119_{\text {fungal, }}$ and Trp407 $7_{\text {bacterial }} / \operatorname{Trp} 425_{\text {fungal }}$ ) are highly conserved in the substrate binding cleft of family $1 \mathrm{BGs}^{18}$ (Fig. 4 and Fig. 5). In addition to these residues, our MD simulations captured the participation of substrate interactions with two others: a $\operatorname{Trp}\left(\operatorname{Tp} 399_{\text {bacterial }} / \operatorname{Trp} 417_{\text {fungal }}\right)$ and a Glu/Asp (Glu409 bacterial $/$ ssp427 fungal) (Fig. 4 and Fig. 5; Supplementary Fig. S4 and S5). We specifically examined the $\mathrm{pH}$ dependence of the non-catalytic interactions and the co-occurrence or lack thereof of these interactions with the key catalytic interaction involving the acidic/basic Glu (Glu166 bacterial $\cdots \mathrm{O} 1$ and Glu165 fungal $\cdots O 1)$.

In the bacterial enzyme, the $\operatorname{Trp} 399_{\text {bacterial }} \cdots \mathrm{O} 4$ interaction occurred at higher abundance at $\mathrm{pH} 5$ than at $\mathrm{pH}$ 6, 7, and 7.5; this pattern is inversely related to the trend of the catalytic Glu166 bacterial $\cdots O 1$ interaction (Fig. 4).

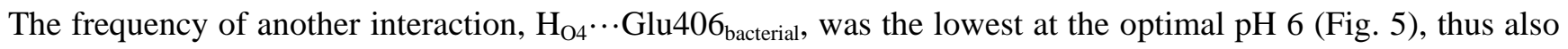
occurring at the inverse trend of the catalytic residue. With the fungal enzyme, the MD simulations reflected a similar abundance pattern for the corresponding non-catalytic interaction (Fig. 6). The Trp417 fungal $\cdots$ O4 interaction, which was absent in the $\mathrm{pH} 6$ and 7 simulations (the two $\mathrm{pH}$ conditions that had the highest occurrence of the catalytic Glu165 fungal $\ldots \mathrm{O} 1$ interaction) was also inversely correlated with the catalytic interaction (Fig. 5). In addition, we found that the $\mathrm{Gln} 16_{\text {fungal }} \cdots \mathrm{O} 4$ interaction occurred statistically less at pH 6 than at the other $\mathrm{pH}$ conditions (Fig. 5). The Asn $164_{\text {fungal }} \cdots \mathrm{O} 2$ interaction displayed a similar frequency pattern to that of the nucleophilic Glu interaction $\left(\mathrm{H}_{\mathrm{O} 2} \cdots \mathrm{Glu} 367_{\text {fungal }}\right)$, with high abundances at $\mathrm{pH} 7$ and 7.5 . An inverse pattern was observed for the occurrence of the His $119_{\text {fungal }} \cdots \mathrm{O} 2$ interaction, which was much lower at $\mathrm{pH} 7$ and 7.5 than at pH 5 and pH 6 (Fig. 5).

The following interactions, which were statistically different at $\mathrm{pH} 6$ when compared with the other $\mathrm{pH}$

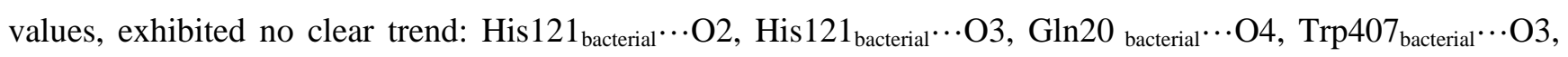
$\mathrm{H}_{\mathrm{O} 6} \cdots$ Glu409 $9_{\text {bacterial, }}$ and Tyr298 bacterial $\cdots \mathrm{O} 1$ for the bacterial enzyme; and, Trp425 fungal $\cdots \mathrm{O} 3$, His1 $19_{\text {fungal }} \cdots \mathrm{O} 3$, and $\mathrm{H}_{\mathrm{O} 6} \cdots$ Asp427 fungal for the fungal enzyme (Supplementary Fig. S4 and Fig. S5). Thus, the pH-dependent significance of these interactions with respect to the catalytic interactions could not be resolved. A noticeable general trend in both the bacterial and fungal BG simulations at $\mathrm{pH} 6$ was the abundance discrepancy between the catalytic interactions, which occurred during $22 \%$ and $17 \%$ of the total simulation time, compared to several non-catalytic interactions, which were observed in nearly every simulation frame (Supplementary Fig. S4 and 
Fig. S5). Specifically, His $121_{\text {bacterial }} \cdots \mathrm{O} 2$, His $121_{\text {bacterial }} \cdots \mathrm{O} 3$, and $\operatorname{Trp} 407_{\text {bacterial }} \cdots \mathrm{O} 3$ as well as $\mathrm{H}_{\mathrm{O} 4} \cdots \mathrm{Glu} 424_{\text {fungal }}$, Gln16 fungal $\cdots \mathrm{O} 2$, and $\mathrm{His} 119_{\text {fungal }} \cdots \mathrm{O} 3$ were relatively abundant across all $\mathrm{pH}$ conditions.

\section{3. pH-Dependent Involvement of Solvated Waters in Substrate Binding Dynamics}

We investigated direct water-substrate interactions as well as water-bridging interactions. A water-bridging interaction was characterized by the occurrence of H-bonds connecting an amino acid residue and the substrate to the same water molecule. The MD simulations revealed the highest amount of direct water-substrate interactions with the solvent-exposed aromatic ring $\left(\mathrm{O} 7\right.$ and $\left.\mathrm{H}_{\mathrm{O} 7}\right)$ of the substrate (Supplementary Fig. S6). Water interactions also occurred with the atoms of the substrate's glucose ring localized inside the binding cleft as well as with the glycosidic O atom (O1) (Supplementary Fig. S6). Specifically, the solvated bacterial BG revealed $\mathrm{H}$-bonds between water molecules and the substrate atoms $\mathrm{O} 4, \mathrm{O} 5, \mathrm{O} 6, \mathrm{H}_{\mathrm{O} 4}$, and $\mathrm{H}_{\mathrm{O} 6}$ and the solvated fungal $\mathrm{BG}$ displayed water interactions with the substrate atoms $\mathrm{O} 3, \mathrm{O} 4, \mathrm{O} 5, \mathrm{O} 6, \mathrm{H}_{\mathrm{O} 3}, \mathrm{H}_{\mathrm{O} 4}$, and $\mathrm{H}_{\mathrm{O} 6}$.

With respect to water bridging interactions, we accounted, considering all the simulation frames $(2 \mathrm{~ns}$ at $2 \mathrm{fs}$ time step), between 634 to 2,712 interactions, which involved 10 to 22 unique amino acid residues (Fig. 7 and Supplementary Fig. S6). Figure 6 illustrates the differences in the water-bridging profiles at the different $\mathrm{pH}$ conditions for each enzyme (Fig. 6 and Supplementary Fig. S6). The total sum of water-bridging interactions was the lowest at the catalytically-optimal pH of 6 for the bacterial enzyme (Supplementary Fig. S7). The total number of water-bridging interactions formed in the fungal enzyme decreased as a function of increasing $\mathrm{pH}$, spanning from 2,712 water-bridges at pH 5 to 634 water-bridges at pH 7.5 (Supplementary Fig. S7).

We also observed distinct water-bridging interaction patterns at different $\mathrm{pH}$ conditions. With the bacterial enzyme, the two most abundant water-bridge interactions at pH 6 were Lys $413_{\text {bacterial }}$ and Tyr $296_{\text {bacterial. }}$. Lys $413_{\text {bacterial }}$ is located outside of the immediate active site and only formed water-bridging interactions at $\mathrm{pH} 6$. Tyr296 $6_{\text {bacterial, }}$ which is located in the immediate active site, recorded a high abundance of water-bridging interactions (Fig. 6), but was found to rarely participate in direct H-bonding with the substrate (Fig. 6). Glu406 $6_{\text {bacterial, }}$ a residue within the immediate active site, was involved in the least abundant water-bridging interaction at $\mathrm{pH} 6$ (Fig. 7). At other $\mathrm{pH}$ conditions, however, Glu406 bacterial water-bridging interactions occurred in high abundance, a pattern which closely follows the abundances of the direct H-bonding between Glu406 bacterial and the substrate (Fig. 5 and Fig. 6).

With respect to the fungal BG enzyme, the most abundant water-bridging interactions at $\mathrm{pH} 6$ involved the residues Asp227 fungal and Ser337 fungal, both of which are outside of the immediate active site (Fig. 6). These interactions occurred either uniquely (Asp227 fungal) or in higher abundance (Ser337 fungal) at $\mathrm{pH} 6$, when compared with the simulations at the other $\mathrm{pH}$ conditions (Fig. 6). In addition, the lowest amount of waterbridging interactions at $\mathrm{pH} 6$ occurred with Asn225 fungal, which is localized outside of the immediate active site; this low abundance was found in all $\mathrm{pH}$ conditions (Fig. 6).

\section{4. pH-Dependent Structural Dynamics in the Enzyme}


The differences in the $\mathrm{pH}$-dependent frequency patterns of both the direct substrate binding and waterbridging interactions suggest conformational changes of the enzymes' structures at different pH conditions (Fig. 4, Fig. 5, and Fig. 6). In order to explore further the influence of $\mathrm{pH}$ on the structural dynamics of each enzyme, we monitored the correlations between the geometrical fluctuations (i.e. RMSD) of the residues involved in changes in ionization states, catalytic interactions, non-catalytic interactions, and water-bridging interactions (Fig. 7 and Fig. 8). Positive correlations between pairs of amino acid residues indicate that these residues are increasing or decreasing their displacement from their original location at similar times throughout the simulation. Negative correlations, conversely, indicate pairs of amino acid residues whose RMSD values move in opposing directions at the same time. Specifically, we focused our analysis on significant RMSD correlations, with either the acidic/basic Glu (Glu166 $6_{\text {bacterial }} /$ Glu165 fungal $)$ or the nucleophilic Glu (Glu352 $2_{\text {bacterial }} /$ Glu367 fungal $)$, which occurred uniquely at the optimal $\mathrm{pH}(\mathrm{pH}$ 6) for enzymatic activity.

The MD simulations of the bacterial BG indicated fewer RMSD correlations at $\mathrm{pH} 6$ than at any other simulated $\mathrm{pH}$ condition. The RMSD values of the residues His $180_{\text {bacterial }}$ (a residue involved in water bridging) and Glu153 bacterial (an ionizable residue which becomes negative at $\mathrm{pH}$ 6), correlated positively with the acidic/basic Glu (Glu165 bacterial) of the bacterial BG (Fig. 7). No uniquely significant positive RMSD correlations were observed with the nucleophilic Glu residue (Glu352 bacterial $_{\text {) }}$ at $\mathrm{pH}$ 6. Furthermore, no negative RMSD correlations were observed with both catalytic Glu residues at $\mathrm{pH} 6$ (Fig. 7). By contrast to the correlation patterns of the structural dynamics in the bacterial enzyme, the corresponding correlation patterns for the fungal enzyme showed a large number of statistically-significant correlations at pH 6 (Fig. 8.. Specifically, positive correlations between the RMSD fluctuations of the acidic/basic Glu165 fungal and those of Trp425 fungal and Tyr298 fungal (both involved in non-catalytic substrate binding) were only observed at pH 6 (Fig. 8). In addition, the RMSD fluctuations of the nucleophilic Glu367 fungal were positively correlated with those of Trp425 fungal (non-catalytic) and Asp256 fungal (ionizable residue), and were negatively correlated with those of His $127_{\text {fungal }}$ (ionizable residue) and Thr431 fungal (water-bridging residue) (Fig. 8).

Collectively, these results show that $\mathrm{pH}$-induced conformational changes, which are evidently unique to the enzyme structure, can impact the correlated movement of proximal and distal amino acid residues (Fig. 7 and Fig. 8). Despite the fact the amino acid residues are highly conserved in the substrate cleft, the fluctuations of neighboring amino acid residues in the active site did not always correlate with each other (Fig. 7 and Fig. 8). Furthermore, structural fluctuations with residues in the substrate-binding cleft were significantly correlated with fluctuations of several residues (ionizable residues and water-bridging interaction residues) localized outside of the immediate active site. And, many of these correlations were found to be pH-and enzymedependent.

\section{Discussion}

\subsection{Changes in Ionization States and Disruption of Substrate Binding Interactions}


In the Introduction, we put forth three hypotheses regarding how changes in $\mathrm{pH}$ may impact substrate binding dynamics. In strong support for the second hypothesis, our findings revealed that the specific residues, which were sensitive to changes in ionization states, were primarily localized on the surface of enzyme, and away from the active site - the only exception was a Glu localized in the active site of the bacterial BG. Mutations of amino acid residues on the surface of enzymes have been shown previously to result in a shift in the optimal $\mathrm{pH}$ for enzyme activity of an endocellulase ${ }^{27}$ and an exocellulase ${ }^{28}$ from $T$. reesi but the mechanisms were not fully elucidated. The experiments with the exocellulase indicated that neighboring carboxyl-carboxyl pair repulsion destabilized the enzyme ${ }^{28}$. In our simulations, the prominent ionizable residues were not localized immediately next to each other. However, it was clear that the increasing negative charges arising from these residues (one Asp, five Glu, and four His residues in the bacterial enzyme; five Asp, three Glu, and four His residues in the fungal enzyme) as a function of increasing $\mathrm{pH}$ resulted in conformational changes in the enzyme (Table 1; Fig. 3). This led to alterations in the substrate binding interactions as evidenced by the $\mathrm{pH}$-dependent frequency patterns of the H-bonding interactions (Fig. 5 and Fig. 6). Our work thus provides for the identification of residues, which could be targeted in protein engineering towards improving enzymatic activity at unfavorable $\mathrm{pH}$ conditions.

In the bacterial BG enzyme, low abundances of the H-bonding interaction between the substrate and Glu166 $_{\text {bacterial }}$ (the acidic/basic Glu) at pH 5 was in agreement with the $\mathrm{pH}$-activity profile ${ }^{2}$ (Fig. 4). At the $\mathrm{pH}$ values higher than $\mathrm{pH} 6$, the dynamics of this interaction did not correlate with the trend in activity reduction observed in experiments $^{2}$ (Fig. 4). Correlation analysis indicated that the $\mathrm{H}_{\mathrm{O} 2} \cdots$ Glu166 bacterial interaction may help align Glu166 in a favorable position for the catalytic interaction, Glu166 bacterial $\cdots \mathrm{O} 1$, to occur at $\mathrm{pH} 6$. Furthermore, the interaction of Glu166 bacterial with $\mathrm{O} 1$ of the substrate correlated positively with the interaction of Glu352 $2_{\text {bacterial }}$ (the nucleophilic Glu) with $\mathrm{H}_{\mathrm{O} 2}$ of the substrate (Fig. 4). This is consistent with the nucleophilic Glu aiding in the positioning of the substrate for the catalytic action, the protonation of $\mathrm{O} 1$, by the acidic/basic Glu residue. The correlation analysis further implies the participation of both Trp399 $9_{\text {bacterial }} \cdots \mathrm{O} 4$ and $\mathrm{H}_{\mathrm{O} 4} \cdots \mathrm{Glu} 406_{\text {bacterial }}$ in the destabilization of the catalytically-optimal substrate orientation in the binding site (Fig. 7).

In contrast, the MD simulations of the fungal BG indicated the highest abundance of H-bond between the nucleophilic Glu (Glu367 fungal $)$ and the substrate at pH 7 and pH 7.5 whereas there was a low abundance of $\mathrm{H}$ bond between the acidic/basic Glu (Glu165 fungal) and the substrate O1 atom (Fig. 5). Thus, a conformational arrangement in which strong interactions of the substrate with the nucleophilic Glu367 did not lead to a favorable orientation of the substrate for the H-bonding interaction with the acidic/basic Glu and the $\mathrm{O} 1$ of the substrate. Because it was determined that the fungal BG exhibited decreasing activity at $\mathrm{pH}$ greater than $6^{2}$, these simulation results implied that the H-bond interaction involving Glu367 fungal may be a barrier for catalysis in the fungal enzyme. Our correlation analysis indicated the supporting participation of $\mathrm{H}_{\mathrm{O} 2} \cdots \mathrm{Glu} 165_{\text {fungal }}$ for the occurrence of the acidic/basic Glu166 fungal $\cdots \mathrm{O} 1$ interaction (Fig. 6 and Fig. 9). Additionally, our dynamics 
results are consistent with the role of the $\mathrm{Gln} 16_{\text {fungal }} \cdots \mathrm{O} 4, \operatorname{Trp} 417_{\text {fungal }} \cdots \mathrm{O} 4$, and Asn $164_{\text {fungal }} \cdots \mathrm{O} 2$ interactions in impeding the favorable catalytic interactions (Fig. 8).

The $\mathrm{pH}$-dependent MD predictions of the interactions between the substrate and the non-catalytic amino acid residues in the substrate binding cleft provided further insights on the consequence of $\mathrm{pH}$ on favorable substrate binding. Moreover, the relatively low abundance of the catalytic acidic/basic Glu interaction with O1, in comparison to several non-catalytic interactions, is consistent with the predominant involvement of noncatalytic interactions with the highly conserved amino acid residues in the initial substrate binding.

\subsection{Water Molecules in the Stabilization of Substrate Binding}

Water molecules have been shown to be essential in stabilizing the transition state and in the removal of the retained portion of the cleaved substrate in the BG hydrolysis pathway ${ }^{18,22-24}$. Less is known, however, about the role of waters in substrate binding of BGs. ${ }^{20}$ In structures of BGs co-crystallized with a bound substrate, several water molecules were localized in the active site as well as within interaction distance of the glycosidic $\mathrm{O}$ atom ${ }^{18}$. A QM/MM modeling reported greater energy contribution of water interactions during stabilization of the intermediate in the active site than during the substrate binding ${ }^{18}$. This QM/MM computation was based on the static position of the water molecules in BG's active site ${ }^{18}$. By modeling explicitly the solvated waters in our MD simulations, we were able to monitor the dynamic interactions of water molecules with the substrate. In addition to the solvation of the solvent-exposed aromatic ring of the substrate, there were water-bridging interactions with several atoms of the substrate ring localized within the pocket of the binding cleft (Supplementary Fig. S5). This is apparently the first time that these interactions have been reported for BG substrate binding.

In agreement with our third hypothesis, our simulations revealed a $\mathrm{pH}$-dependent network of water-bridging interactions between the substrate and amino acid residues inside and outside of the immediate active site (Fig. 7). We note that Lys $413_{\text {bacterial }}$, Asp $227_{\text {fungal }}$, Ser $337_{\text {fungal }}$, all of which are located outside of the active site, were able to participate in substrate binding through water-bridging connections (Fig. 6). These findings corroborate a greater and more dynamic role of water molecules in substrate stabilization than previously thought.

For instance, Tyr296 $6_{\text {bacterial, }}$ found in the immediate active site of the bacterial BG, infrequently interacted directly with the substrate at $\mathrm{pH} 6$, but participated in a large amount of water-bridging interactions. This is consistent with a conformational arrangement of the active site wherein Tyr296 bacterial does not interact directly with the substrate but still adopts an orientation that allows for multiple water-bridging interactions (Fig. 4 and Fig. 6). On the other hand, Glu406 $6_{\text {bacterial, }}$ a residue in the immediate active site of the bacterial BG, participated in markedly low abundances in both direct and water-bridging interactions with the substrate at $\mathrm{pH} 6$ whereas were abundant at other $\mathrm{pH}$ values, thus presenting a conformation of the enzyme in which either direct or waterbridge interactions between Glu406 bacterial and the substrate were not critical. Connections between waterbridging interaction abundances and direct residue-substrate interactions were less evident in the fungal BG 
simulations. Water bridging profiles thus expand our view of which amino acids are involved in substrate stabilization.

\section{Implications and Caveats}

We conducted MD simulations to gain insights on the effects of $\mathrm{pH}$ on the substrate binding dynamics, the initial step of catalysis, in two family $1 \mathrm{BG}$ enzymes from T. reesi and C. cellulovorans. Experimental determinations of structures for one BG enzyme are obtained typically at one aqueous $\mathrm{pH}$ condition that yields the best crystals. ${ }^{2,19}$ Therefore, it is challenging to resolve the structural dynamics underlying the $\mathrm{pH}$-dependent BG catalytic action on the substrate, albeit it is well known that enzymatic activity of BGs and related enzymes is influenced significantly by the aqueous $\mathrm{pH}$ conditions ${ }^{2,16,50}$. Furthermore, the direct experimental characterization of the role of interacting water molecules in BG substrate binding is limiting ${ }^{18}$, necessitating complementary insights from molecular modeling. Our computational study presents the first molecular perspective on the consequence of $\mathrm{pH}$-dependent conformational changes on substrate-binding interactions in BGs.

Changes in ionizable residues on the enzyme surface induced disruptive changes in the favorable conformation for substrate binding interactions with the catalytic residues. Our findings further demonstrated that the role of the catalytic nucleophilic Glu residue in either facilitating or disrupting the catalytic substrate binding by the acidic/basic Glu was dependent on the enzyme structure and the $\mathrm{pH}$ condition. In addition, we identified substrate binding interactions with specific non-catalytic residues which may be unfavorable for the forwarding steps in catalytic pathway. The explicit solvation identified several water-bridging interactions, which were important at the optimal $\mathrm{pH}$ for enzyme activity, were disrupted at other $\mathrm{pH}$ values due to structural re-arrangements in the enzyme conformation. Furthermore, correlation analysis of amino acids' movements indicated that the synchronicity (or lack thereof) of $\mathrm{pH}$-dependent geometrical fluctuations in a network of amino acids, which were localized both outside and inside the substrate binding cleft, was responsible for the substrate binding specificity.

The relevance of our findings should be considered in relation to two important factors. First, we conducted our analysis using equilibrated structures obtained during short-time dynamics conducted for several nanoseconds. We have also conducted longer simulations (at $200 \mathrm{~ns}$ ), which are typical in MD simulation studies. However, our findings revealed such long-time simulations are not appropriate to probe the substrate binding, especially under unfavorable $\mathrm{pH}$ conditions. In such conditions, we found that the substrate migrated outside the substrate binding cleft and interacted with residues on the periphery of the active site. Our findings thus indicated that, in order to increase the sampling set of substrate interactions specifically in the active site, a more appropriate approach is to equilibrate a range of initial docked substrate structures for short-time dynamics time. Future explorations of the substrate affinity to residues outside of the active site will provide insights into the influence of $\mathrm{pH}$ on the tunneling pathway of the substrate towards the active site. Second, an evaluation of 
the $\mathrm{pH}$-dependent structural dynamics on the entire catalytic reaction pathway is requisite to a comprehensive understanding of the structural basis for the pH-dependent activity of BGs. The present study provides an account of the $\mathrm{pH}$-dependent substrate binding interactions in response to $\mathrm{pH}$-induced conformational dynamics, thus laying the foundation for future investigations on the influence of $\mathrm{pH}$ on the subsequent steps in the catalytic pathway.

\section{ACKNOWLEDGMENT}

We thank Hua Wei, Ed Park, Amy Pochodylo, and Samantha Sasnow for technical support, and Chantal Koechli for aid in graphics generation. D.F.F. acknowledges an Integrative Graduate Education and Research Traineeship (IGERT) research fellowship and a Graduate Research Fellowship, both from the U.S. National Science Foundation.

\section{REFERENCES}

(1) Singhania, R. R.; Patel, K.; Sukumaran, R.; Larroche, C.; Pandey, A. Role and significance of betaglucosidases in the the hydrolysis of cellulose for bioethanol production. Bioresour. Technol. 2013, 127, 500-507.

(3) Wieder, W. R.; Bonan, G. B.; Allison, S. D. Global soil carbon projections are improved by modelling microbial processes. Nat. Clim. Change 2013, 3, 909-912.

(4) Knight, T. R.; Dick, R. P. Differentiating microbial and stabilized $\beta$-glucosidase activity relative to soil quality. Soil Biol. Biochem. 2004, 36, 2089-2096.

(5) Mariscal-Sancho, I.; Santano, J.; Mendiola, M.-A.; Peregrina, F.; Espejo, R. Carbon Dioxide Emission Rates and [beta]-Glucosidase Activity in Mediterranean Ultisols Under Different Soil Management. Soil Sci. Sept. 2010 2010, 175, 453-460.

(6) Teugjas, H.; Väljamäe, P. Selecting $\beta$-glucosidases to support cellulases in cellulose saccharification. Biotechnol. Biofuels 2013, 6, 105.

(7) Jørgensen, H.; Kristensen, J. B.; Felby, C. Enzymatic conversion of lignocellulose into fermentable sugars: challenges and opportunities. Biofuels Bioprod. Biorefining 2007, 1, 119-134.

(8) Percival Zhang, Y.-H.; Himmel, M. E.; Mielenz, J. R. Outlook for cellulase improvement: Screening and selection strategies. Biotechnol. Adv. 2006, 24, 452-481.

(9) Zimmerman, A. R.; Ahn, M.-Y. Organo-Mineral-Enzyme Interaction and Soil Enzyme Activity. In Soil Enzymology; Shukla, G.; Varma, A., Eds.; Soil Biology; Springer Berlin Heidelberg, 2011; pp. 271-292. 
(10) Acosta-Martínez, V.; Tabatabai, M. A. Enzyme activities in a limed agricultural soil. Biol. Fertil. Soils 2000, 31, 85-91.

(11) Lauber, C. L.; Hamady, M.; Knight, R.; Fierer, N. Pyrosequencing-Based Assessment of Soil pH as a Predictor of Soil Bacterial Community Structure at the Continental Scale. Appl. Environ. Microbiol. 2009, 75, 5111-5120.

(12) Lan, T. Q.; Lou, H.; Zhu, J. Y. Enzymatic Saccharification of Lignocelluloses Should be Conducted at Elevated pH 5.2-6.2. BioEnergy Res. 2013, 6, 476-485.

(13) Creighton, T. E. Proteins: Structures and Molecular Properties; Macmillan, 1993.

(14) Schomburg, I.; Chang, A.; Placzek, S.; Sohngen, C.; Rother, M.; Lang, M.; Munaretto, C.; Ulas, S.; Stelzer, M.; Grote, A.; et al. BRENDA in 2013: integrated reactions, kinetic data, enzyme function data, improved disease classification: new options and contents in BRENDA. Nucleic Acids Res. 2013, 41, D764-D772.

(15) Murao, S.; Sakamoto, R.; Arai, M. Cellulases of Aspergillus aculeatus. Methods Enzymol. 1988, 160, 274-299.

(16) Zibaee, A.; Bandani, A. R.; Ramzi, S. Enzymatic properties of alpha- and beta-glocusidases extracted from midgut and salivary glands of rice striped stem borer, Chilo suppressalis Walker (Lepidoptera: Pyralidae). C. R. Biol. 2009, 332, 633-641.

(17) Vuong, T. V.; Wilson, D. B. Glycoside hydrolases: Catalytic base/nucleophile diversity. Biotechnol. Bioeng. 2010, 107, 195-205.

(18) Badieyan, S.; Bevan, D. R.; Zhang, C. Probing the Active Site Chemistry of $\beta$-Glucosidases along the Hydrolysis Reaction Pathway. Biochemistry (Mosc.) 2012, 51, 8907-8918.

(19) Jeng, W.-Y.; Wang, N.-C.; Lin, C.-T.; Chang, W.-J.; Liu, C.-I.; Wang, A. H.-J. High-resolution structures of Neotermes koshunensis $\beta$-glucosidase mutants provide insights into the catalytic mechanism and the synthesis of glucoconjugates. Acta Crystallogr. D Biol. Crystallogr. 2012, 68, 829-838.

(20) Chuenchor, W.; Pengthaisong, S.; Robinson, R. C.; Yuvaniyama, J.; Svasti, J.; Cairns, J. R. K. The structural basis of oligosaccharide binding by rice BGlu1 beta-glucosidase. J. Struct. Biol. 2011, 173, 169-179.

(21) Withers, S. G.; Rupitz, K.; Trimbur, D.; Warren, R. A. J. Mechanistic consequences of mutation of the active site nucleophile Glu 358 in Agrobacterium .beta.-glucosidase. Biochemistry (Mosc.) 1992, 31, 9979-9985.

(22) White, A.; Rose, D. R. Mechanism of catalysis by retaining $\beta$-glycosyl hydrolases. Curr. Opin. Struct. Biol. 1997, 7, 645-651.

(23) Vocadlo, D. J.; Davies, G. J. Mechanistic insights into glycosidase chemistry. Curr. Opin. Chem. Biol. 2008, 12, 539-555.

(24) Wang, J.; Hou, Q.; Dong, L.; Liu, Y.; Liu, C. QM/MM studies on the glycosylation mechanism of rice BGlu1 $\beta$-glucosidase. J. Mol. Graph. Model. 2011, 30, 148-152. 
(25) Kaper, T.; van Heusden, H. H.; van Loo, B.; Vasella, A.; van der Oost, J.; de Vos, W. M. Substrate Specificity Engineering of $\beta$-Mannosidase and $\beta$-Glucosidase from Pyrococcus by Exchange of Unique Active Site Residues†. Biochemistry (Mosc.) 2002, 41, 4147-4155.

(26) Huber, R. E.; Hlede, I. Y.; Roth, N. J.; McKenzie, K. C.; Ghumman, K. K. His-391 of $\beta$-galactosidase (Escherichia coli) promotes catalyes by strong interactions with the transition state. Biochem. Cell Biol. 2001, 79, 183-193.

(27) Wang, T.; Liu, X.; Yu, Q.; Zhang, X.; Qu, Y.; Gao, P.; Wang, T. Directed evolution for engineering pH profile of endoglucanase III from Trichoderma reesei. Biomol. Eng. 2005, 22, 89-94.

Wohlfahrt, G.; Pellikka, T.; Boer, H.; Teeri, T. T.; Koivula, A. Probing pH-Dependent Functional Elements in Proteins: Modification of Carboxylic Acid Pairs in Trichoderma reesei Cellobiohydrolase Cel6A $†$. Biochemistry (Mosc.) 2003, 42, 10095-10103.

(29) Monard, G.; Prat-Resina, X.; González-Lafont, A.; Lluch, J. M. Determination of enzymatic reaction pathways using QM/MM methods. Int. J. Quantum Chem. 2003, 93, 229-244.

(30) Senn, H. M.; Thiel, W. QM/MM studies of enzymes. Curr. Opin. Chem. Biol. 2007, 11, 182-187.

(31) Karplus, M.; Kuriyan, J. Molecular dynamics and protein function. Proc. Natl. Acad. Sci. U. S. A. 2005, 102, 6679-6685.

(32) Machuqueiro, M.; Baptista, A. M. The pH-Dependent Conformational States of Kyotorphin: A ConstantpH Molecular Dynamics Study. Biophys. J. 2007, 92, 1836-1845.

(33) Bürgi, R.; Kollman, P. A.; van Gunsteren, W. F. Simulating proteins at constant pH: An approach combining molecular dynamics and Monte Carlo simulation. Proteins Struct. Funct. Bioinforma. 2002, 47, 469-480.

(34) Langella, E.; Improta, R.; Barone, V. Checking the pH-Induced Conformational Transition of Prion Protein by Molecular Dynamics Simulations: Effect of Protonation of Histidine Residues. Biophys. J. 2004, 87, 3623-3632.

(35) Tan, J.; Verschueren, K. H. G.; Anand, K.; Shen, J.; Yang, M.; Xu, Y.; Rao, Z.; Bigalke, J.; Heisen, B.; Mesters, J. R.; et al. pH-dependent Conformational Flexibility of the SARS-CoV Main Proteinase (Mpro) Dimer: Molecular Dynamics Simulations and Multiple X-ray Structure Analyses. J. Mol. Biol. 2005, 354, $25-40$

(36) Machuqueiro, M.; Baptista, A. M. Acidic range titration of HEWL using a constant-pH molecular dynamics method. Proteins Struct. Funct. Bioinforma. 2008, 72, 289-298.

Zhou, J.-M.; Zhou, J.-H.; Meng, Y.; Chen, M.-B. Molecular Dynamics Simulation of Iminosugar Inhibitor-Glycosidase Complex: Insight into the Binding Mechanism of 1-Deoxynojirimycin and Isofagomine toward $\beta$-Glucosidase. J. Chem. Theory Comput. 2006, 2, 157-165.

Brooks, B. R.; Bruccoleri, R. E.; Olafson, B. D.; States, D. J.; Swaminathan, S.; Karplus, M. CHARMM: A program for macromolecular energy, minimization, and dynamics calculations. J. Comput. Chem. 1983, 4, 187-217. 
(39) Accelrys Software Inc. Discovery Studio Modeling Environment; Accelrys Software Inc.: San Diego, 2013.

(40) Brooks, B. R.; Brooks, C. L.; Mackerell, A. D.; Nilsson, L.; Petrella, R. J.; Roux, B.; Won, Y.; Archontis, G.; Bartels, C.; Boresch, S.; et al. CHARMM: The biomolecular simulation program. J. Comput. Chem. 2009, 30, 1545-1614.

(41) Spassov, V. Z.; Yan, L. A fast and accurate computational approach to protein ionization. Protein Sci. 2008, 17, 1955-1970.

(42) Wu, G.; Robertson, D. H.; Brooks, C. L.; Vieth, M. Detailed analysis of grid-based molecular docking: A case study of CDOCKER-A CHARMm-based MD docking algorithm. J. Comput. Chem. 2003, 24, 1549-1562.

(43) Roche, O.; Kiyama, R.; Brooks, C. L. Ligand-Protein DataBase: Linking Protein-Ligand Complex Structures to Binding Data. J. Med. Chem. 2001, 44, 3592-3598.

(44) Verdonk, M. L.; Cole, J. C.; Hartshorn, M. J.; Murray, C. W.; Taylor, R. D. Improved protein-ligand docking using GOLD. Proteins Struct. Funct. Bioinforma. 2003, 52, 609-623.

(45) Baptista, A. M.; Teixeira, V. H.; Soares, C. M. Constant-pH molecular dynamics using stochastic titration. J. Chem. Phys. 2002, 117, 4184-4200.

(46) Dlugosz, M.; Antosiewicz, J. M. Constant-pH molecular dynamics simulations: a test case of succinic acid. Chem. Phys. 2004, 302, 161-170.

(47) Campos, S. R. R.; Machuqueiro, M.; Baptista, A. M. Constant-pH Molecular Dynamics Simulations Reveal a $\beta$-Rich Form of the Human Prion Protein. J. Phys. Chem. B 2010, 114, 12692-12700.

(48) Baker, E. N.; Hubbard, R. E. Hydrogen bonding in globular proteins. Prog. Biophys. Mol. Biol. 1984, 44, 97-179.

(49) Bissantz, C.; Kuhn, B.; Stahl, M. A Medicinal Chemist's Guide to Molecular Interactions. J. Med. Chem. 2010, 53, 5061-5084.

(50) Yan, S.; Wu, G. Prediction of optimal pH in hydrolytic reaction of beta-glucosidase. Appl. Biochem. Biotechnol. 2013, 169, 1884-1894. 
Table 1. List of Amino Acid Residues with pH-Dependent Ionization States in the Bacterial and Fungal BG Enzymes.

\begin{tabular}{|c|c|c|c|c|c|}
\hline Enzyme & $\begin{array}{l}\text { Ionizable } \\
\text { Residue }\end{array}$ & pH 5 & pH 6 & $\mathrm{pH} 7$ & $\begin{array}{l}\mathrm{pH} \\
7.5\end{array}$ \\
\hline \multirow[t]{10}{*}{ Bacterial } & Asp252 & 0 & - & - & - \\
\hline & Glu22 & 0 & 0 & - & - \\
\hline & Glu153 & 0 & - & - & - \\
\hline & Glu286 & 0 & - & - & - \\
\hline & Glu370 & 0 & - & - & - \\
\hline & Glu406 & 0 & 0 & 0 & - \\
\hline & His49 & + & 0 & 0 & 0 \\
\hline & His240 & + & + & 0 & 0 \\
\hline & His340 & + & + & + & 0 \\
\hline & His419 & + & + & 0 & 0 \\
\hline \multirow[t]{12}{*}{ Fungal } & Asp105 & 0 & - & - & - \\
\hline & Asp121 & 0 & 0 & - & - \\
\hline & Asp142 & 0 & - & - & - \\
\hline & Asp227 & 0 & - & - & - \\
\hline & Asp256 & 0 & - & - & - \\
\hline & Glu18 & 0 & - & - & - \\
\hline & Glu144 & 0 & - & - & - \\
\hline & Glu244 & 0 & - & - & - \\
\hline & His127 & + & + & 0 & 0 \\
\hline & His194 & + & + & + & 0 \\
\hline & His 287 & + & + & + & 0 \\
\hline & His305 & + & + & + & 0 \\
\hline
\end{tabular}




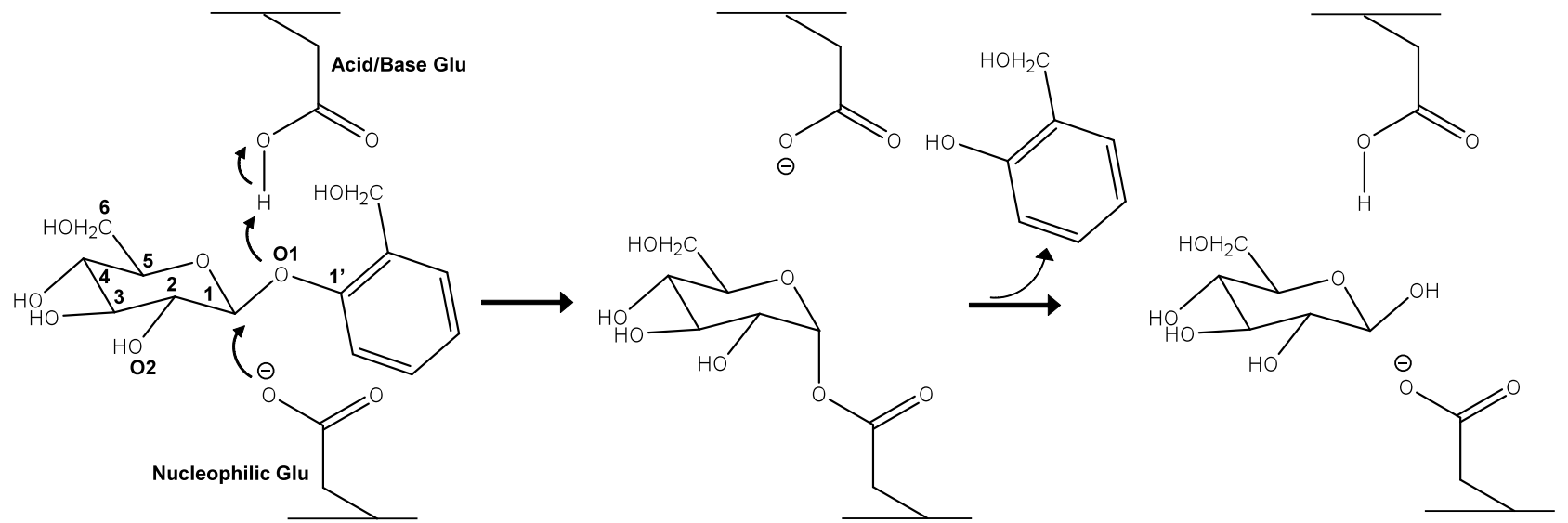

Scheme 1. Schematic representation of the BG catalytic action on the substrate (salicin).
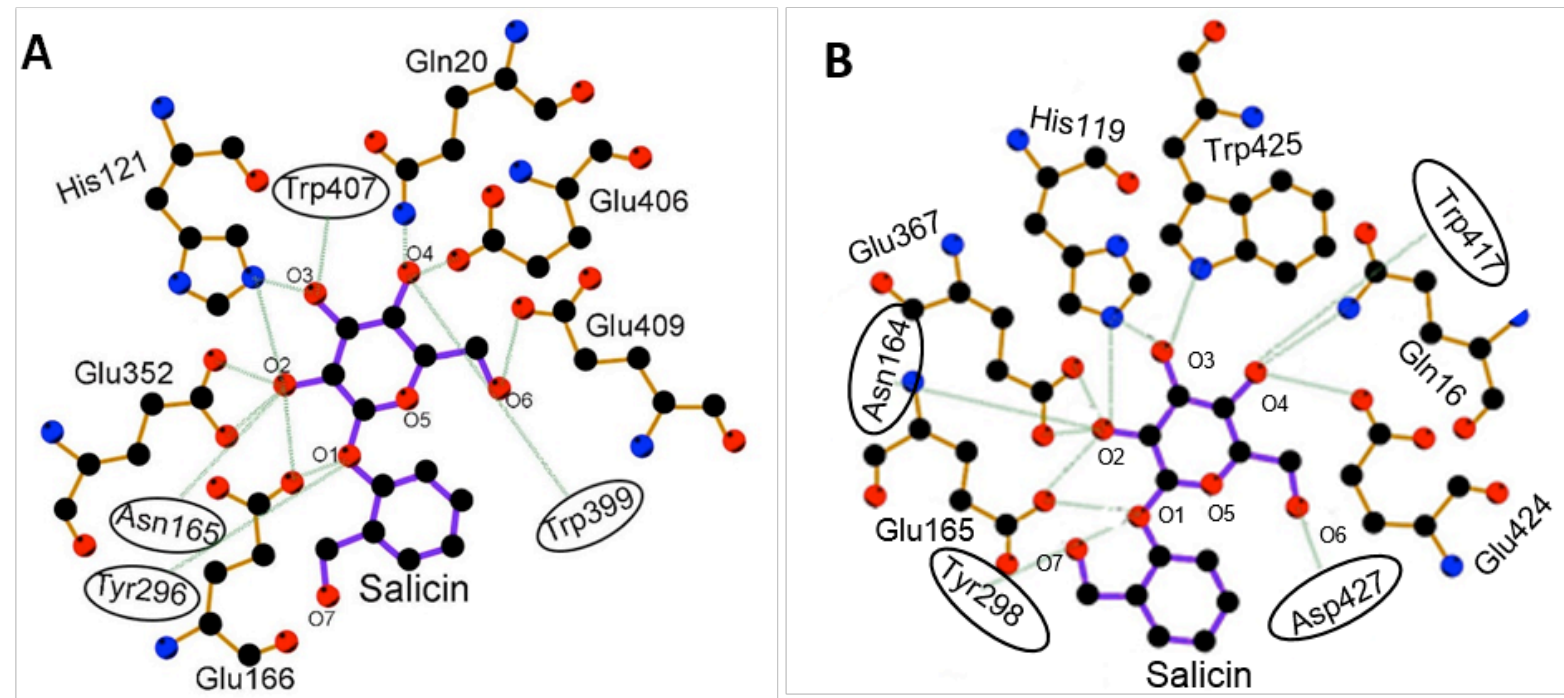

Fig. 1. Schematic diagrams of a BG active site from (A) the bacterium Clostridium cellulovorans and (B) from the fungus Trichoderma reesi. Possible H-bonds that can form between the amino acids and the substrate (salicin) are shown in green. These H-bonds were monitored for interactions throughout the course of simulation. 

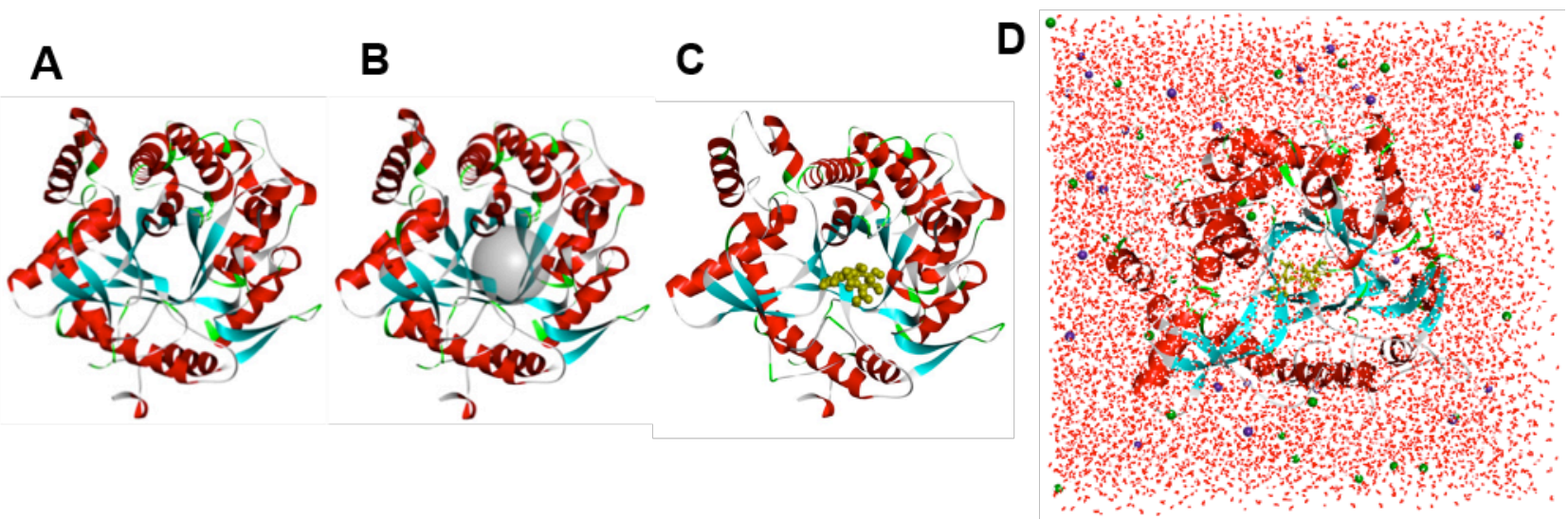

Fig. 2. Modeling workflow for obtaining preliminary structures of a $B G$ in a hydrated environment: (A) downloaded $\mathrm{X}$-ray structure of enzyme was prepared at a specific $\mathrm{pH},(\mathrm{B})$ preliminary determination of interaction region of substrate (shown by gray sphere), (C) docking of substrate (shown in yellow), and (D) view of the hydration of system using explicit solvated water molecules in a $\mathrm{NaCl}$ solution $(\mathrm{Na}$ and $\mathrm{Cl}$ ions are represented as purple and green spheres, respectively). The secondary structure of the enzyme is portrayed in red for alpha helices, blue for beta-sheets, and green for loops. 


\section{A}

pH 5
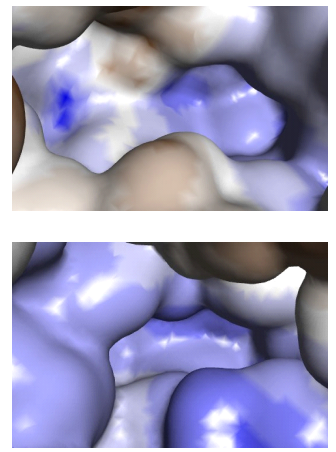

pH 6

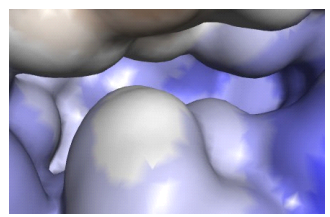

pH 7

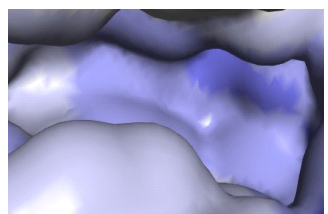

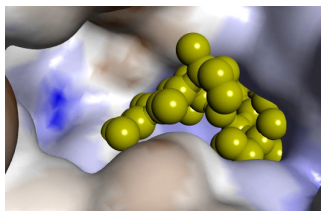
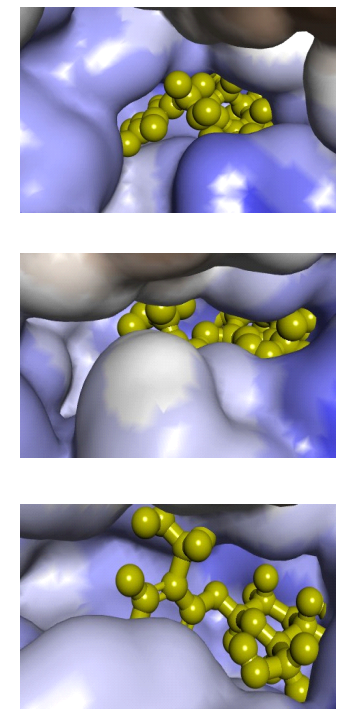

B

pH 5
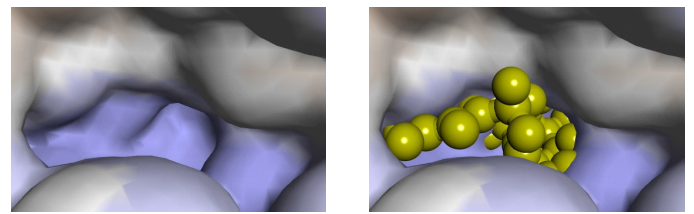

pH 6
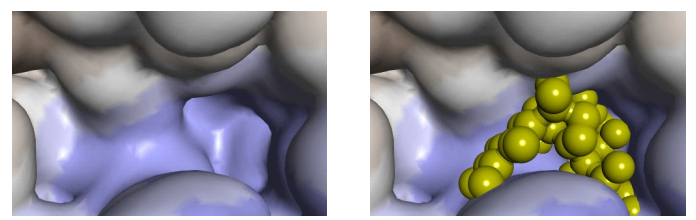

pH 7
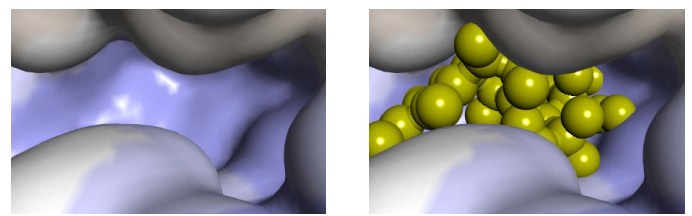

$\mathrm{pH} 7.5$
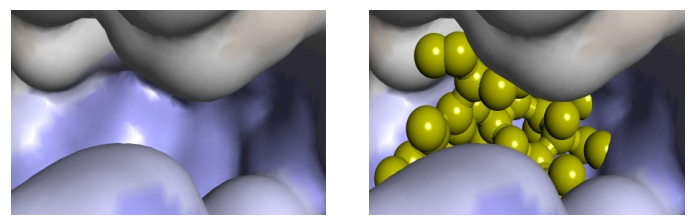

Fig. 3. A close-up snapshot of hydrophobic (brown) and hydrophilic (blue) regions of the substrate-binding pocket in MD-equilibrated configuration of the bacterial (A) and fungal (B) BGs at $\mathrm{pH} 5, \mathrm{pH} 6, \mathrm{pH} 7$, and $\mathrm{pH} 7.5$ (from top to bottom, respectively) presented without (left) and with (right) the substrate. Surface maps of hydrophobic and hydrophilic regions over the entire surface of the enzymes are shown in supplementary Fig. S3. 

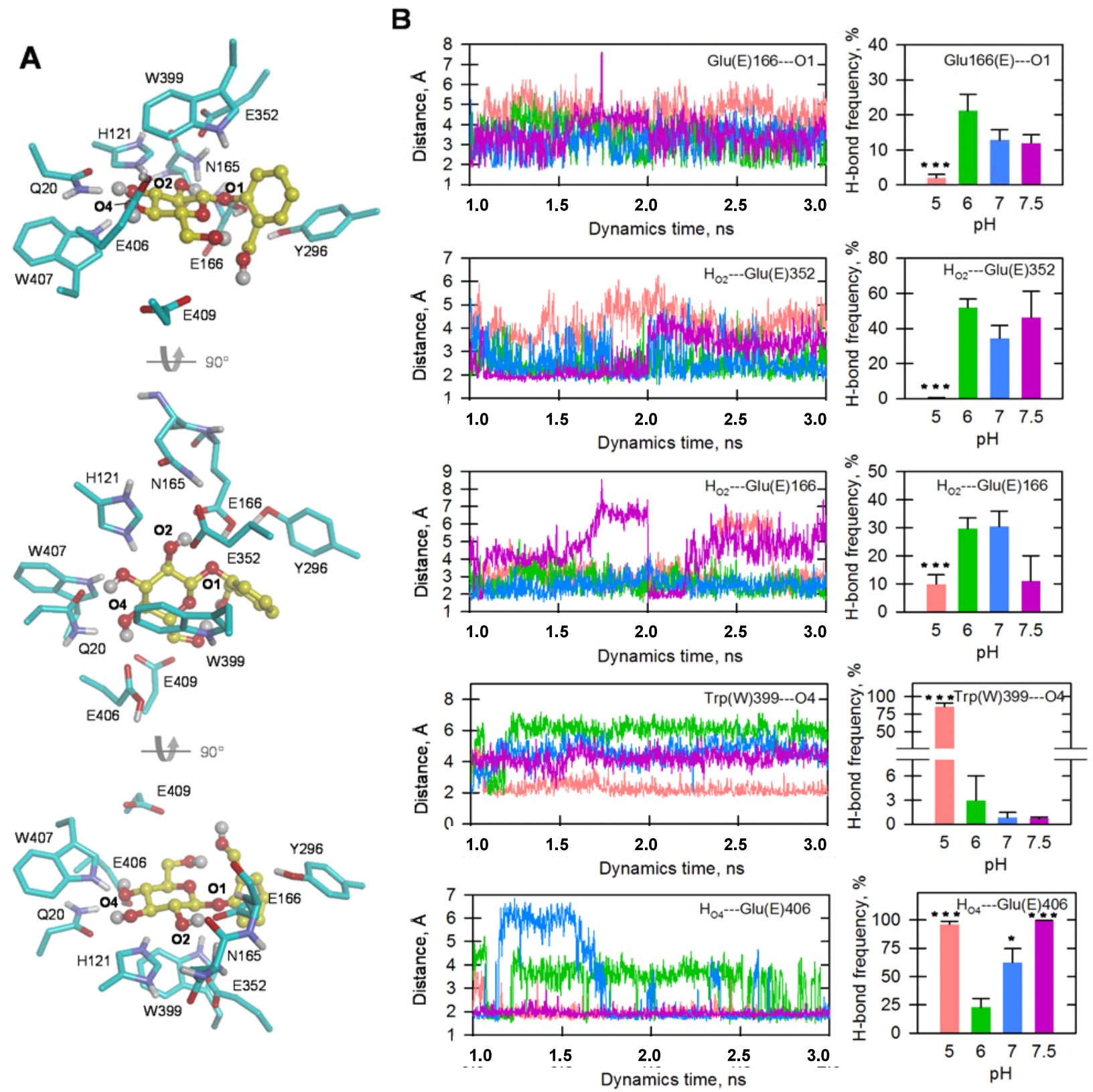

Fig. 4. (A) Close-up views of the substrate in the active site of a BG from the bacterium C. cellulovorans and (B) distances (left) and frequency of $\mathrm{H}$-bond abundances (right) between active site residues and the substrate in the MD-simulated configurations at $\mathrm{pH} 5$ (pink), $\mathrm{pH} 6$ (green), $\mathrm{pH} 7$ (blue), and $\mathrm{pH} 7.5$ (purple). Statistical analysis: pvalue $<0.05=*$; p-value $<0.001=* * *$. 

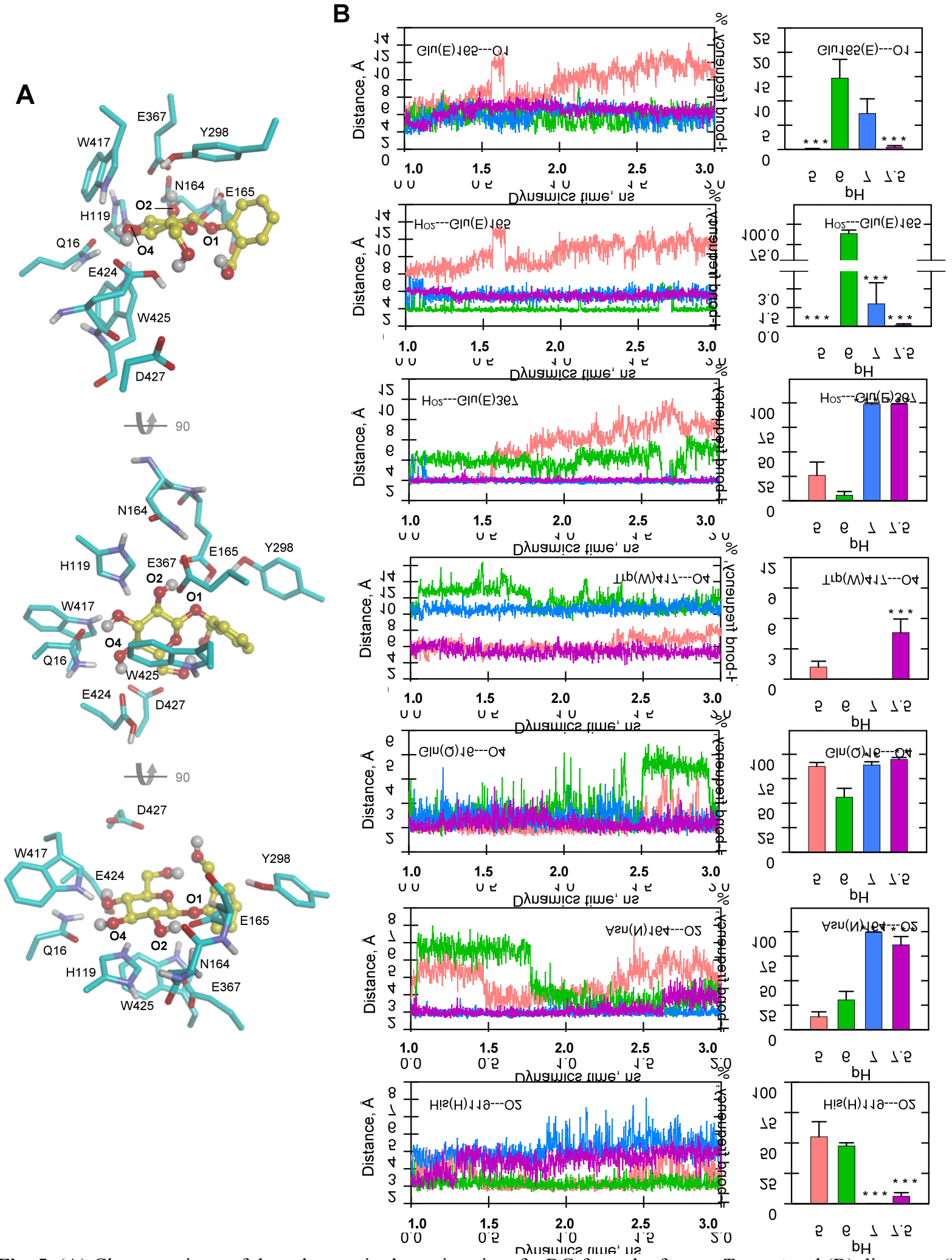

Fig. 5. (A) Close-up views of the substrate in the active site of a BG from the fungus $T$. reesi and (B) distances (left) and frequency of H-bond abundances (right) between active site residues and the substrate in the MD-simulated 
configurations at $\mathrm{pH} 5$ (pink), $\mathrm{pH} 6$ (green), $\mathrm{pH} 7$ (blue), and $\mathrm{pH} 7.5$ (purple). Statistical analysis: $\mathrm{p}$ value $<0.01=$ $* *$, p value $<0.001=* * *$ ). 


\section{A}

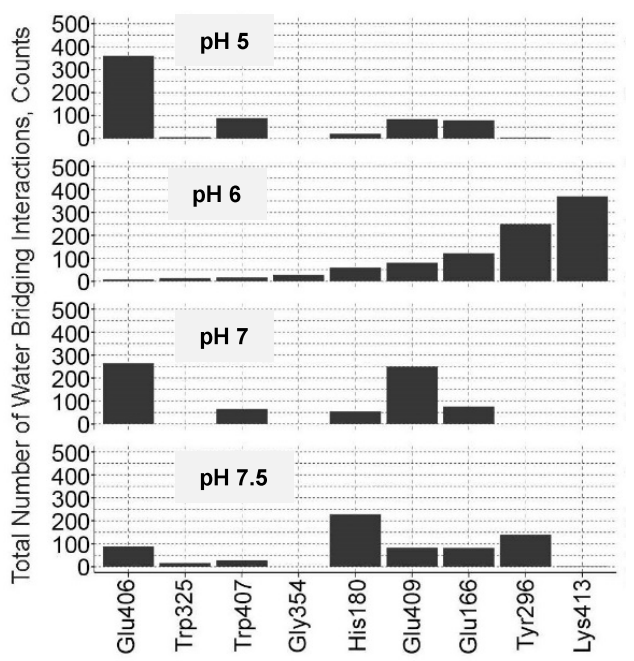

Amino Acid Involved in Water Bridge Interaction

B

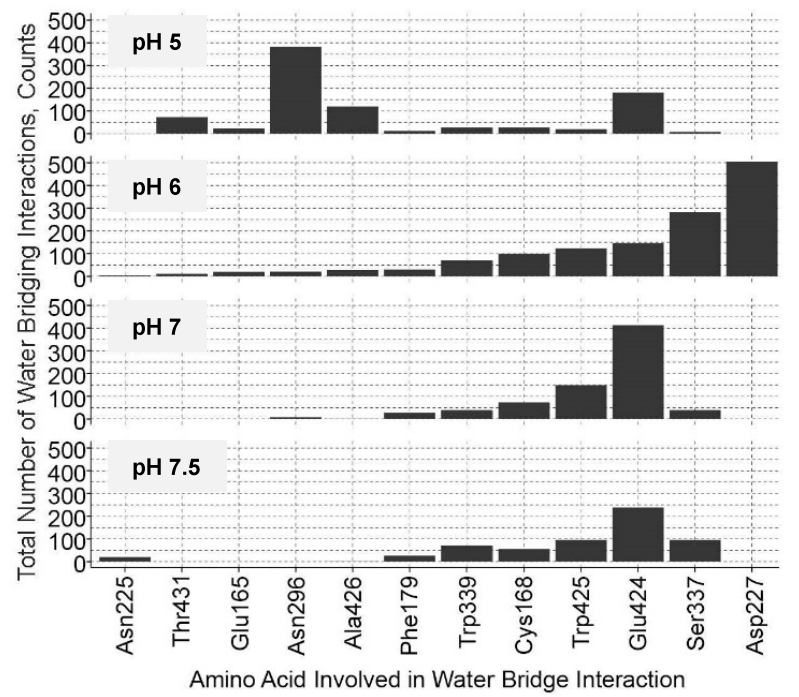

Fig. 6. MD prediction of total amount of water-bridging interactions between the substrate and the bacterial BG (A) and the fungal $\mathrm{BG}(\mathrm{B})$ enzymes at the different $\mathrm{pH}$ values. Amino acids are listed (from left to right) according to their increasing participation in water-bridging interactions at $\mathrm{pH} 6$. 

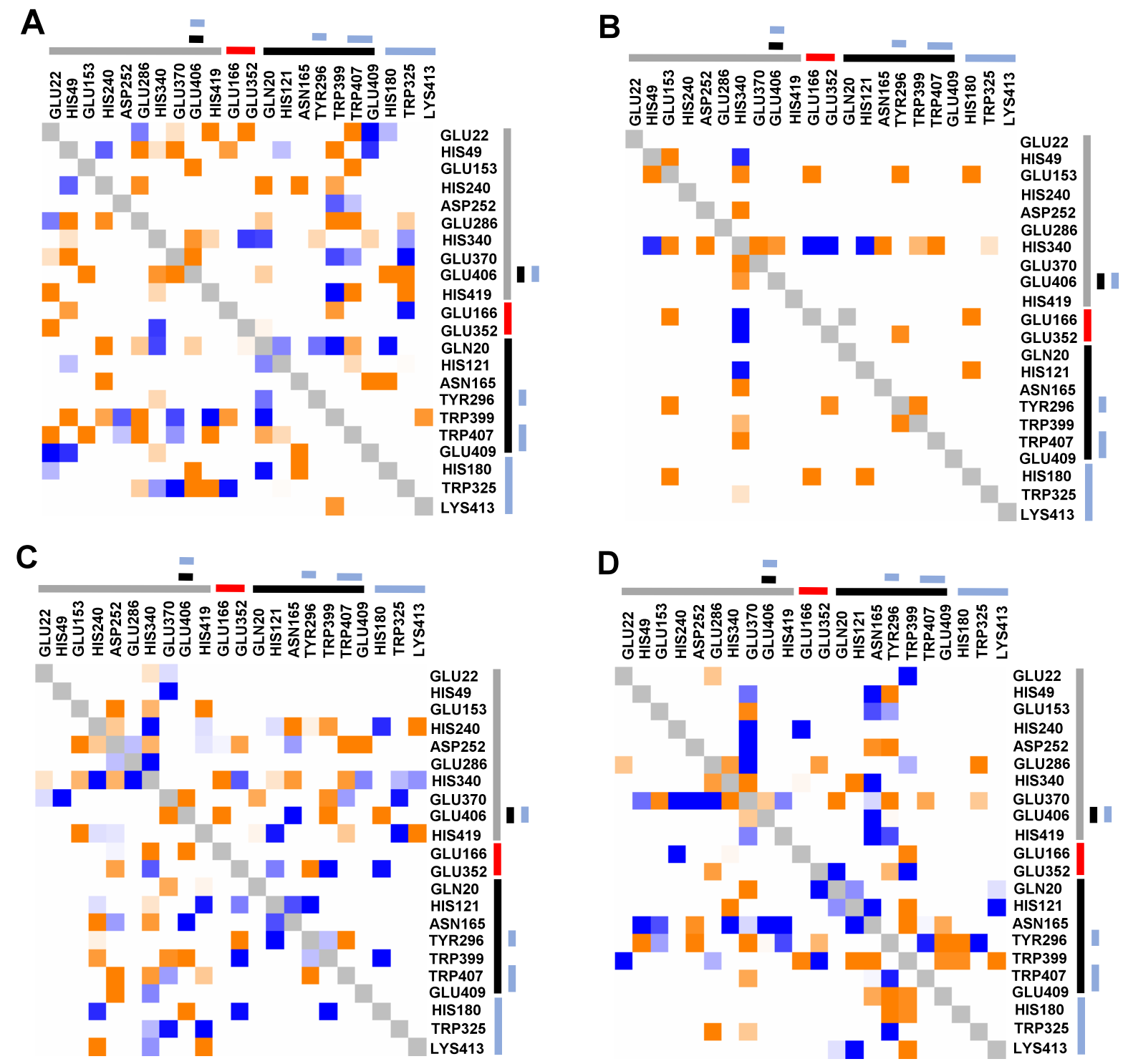

Fig. 7. Correlation matrices of amino acid-resolved structural dynamics of the bacterial $\mathrm{BG}$ enzyme at $\mathrm{pH} 5(\mathrm{~A}), \mathrm{pH}$ 6 (B), $\mathrm{pH} 7$ (C), and $\mathrm{pH} 7.5$ (D). The RMSD of each amino acid of interest was monitored over the course of the MD simulation. Positive, negative, non-significant, and self-pairing correlations are shown, respectively, in orange, blue, white, and grey squares. The bars alongside the residue labels designate residues that change ionization states (gray), catalytic residues (red), non-catalytic residue involved in direct substrate binding (black), residues involved in water-bridging interactions with the substrate (light blue). 

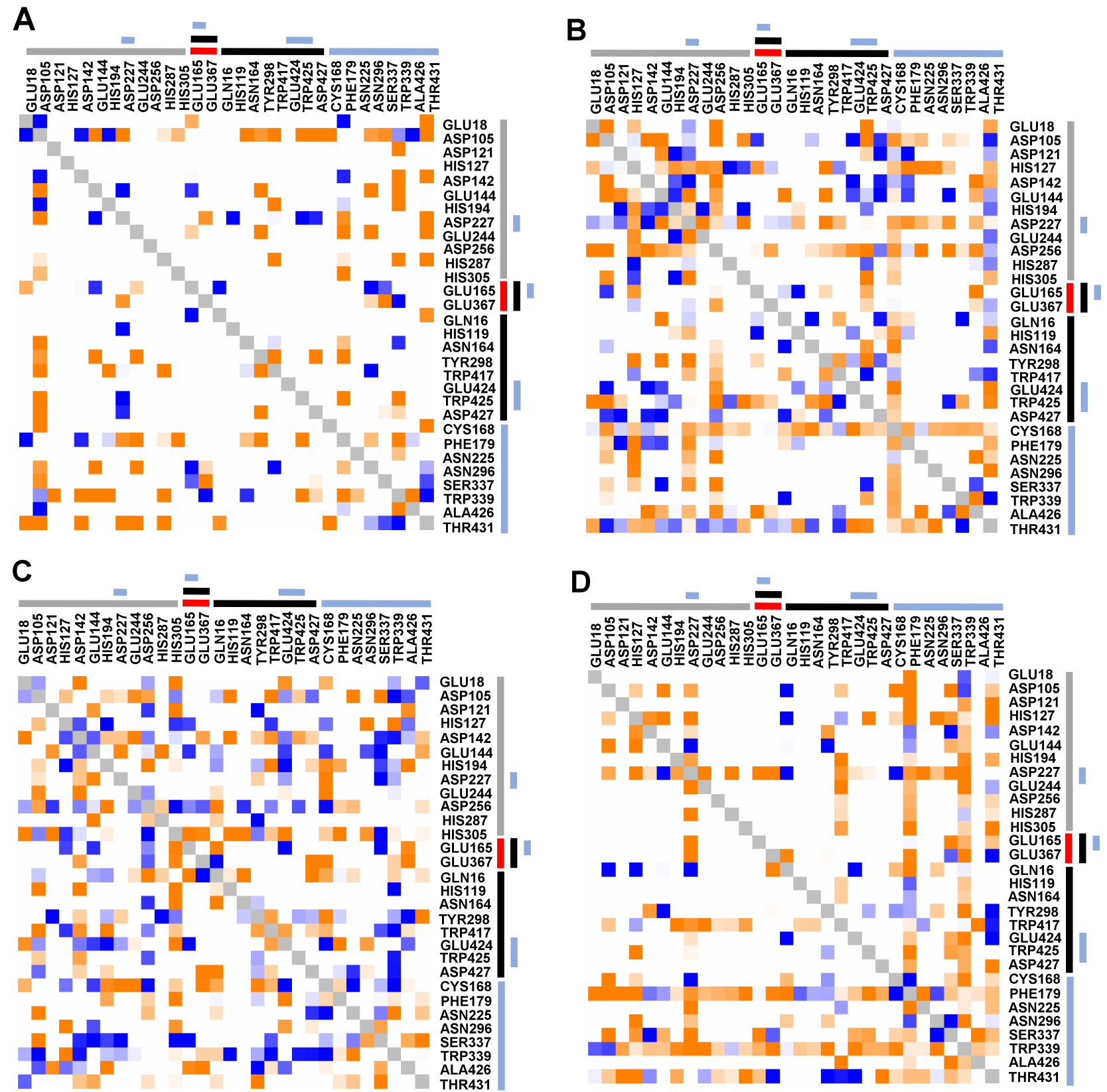

Fig. 8. Correlation matrices of amino acid-resolved structural dynamics of the fungal $\mathrm{BG}$ enzyme at $\mathrm{pH} 5$ (A), $\mathrm{pH} 6$ (B), $\mathrm{pH} 7$ (C), and $\mathrm{pH} 7.5$ (D). The RMSD of each amino acid of interest was monitored over the course of the MD simulation. Positive, negative, non-significant, and self-pairing correlations are shown, respectively, in orange, blue, white, and grey squares. The bars alongside the residue labels designate residues that change ionization states (gray), catalytic residues (red), non-catalytic residue involved in direct substrate binding (black), residues involved in water-bridging interactions with the substrate (light blue). 